\title{
CORRECTION
}

\section{Correction to: Diagnostic options for blunt abdominal trauma}

\author{
Gerhard Achatz ${ }^{1}$ (I) Kerstin Schwabe ${ }^{2} \cdot$ Sebastian Brill ${ }^{2} \cdot$ Christoph Zischek $^{3} \cdot$ Roland Schmidt $^{2} \cdot$ Benedikt Friemert $^{1}$. \\ Christian Beltzer ${ }^{2}$
}

Published online: 14 August 2020

(c) Springer-Verlag GmbH Germany, part of Springer Nature 2020

\section{Correction to: \\ European Journal of Trauma and Emergency Surgery https://doi.org/10.1007/s00068-020-01405-1}

The original version of this article unfortunately contained a mistake. In the author list, the first and last names were tagged incorrectly. The corrected author list is given above.

The original article has been corrected.

The original article can be found online at https://doi.org/10.1007/ s00068-020-01405-1.

\section{Gerhard Achatz}

GerhardAchatz@Bundeswehr.org

1 Department for Trauma Surgery and Orthopaedics, Reconstructive and Septic Surgery, Sportstraumatology, German Armed Forces Hospital Ulm, Oberer Eselsberg 40, 89081 Ulm, Germany

2 Department for General-, Visceral- and Thoracic-Surgery, German Armed Forces Hospital Ulm, Oberer Eselsberg 40, 89081 Ulm, Germany

3 Department for Vascular- and Endovascular-Surgery, German Armed Forces Hospital Ulm, Ulm, Germany 